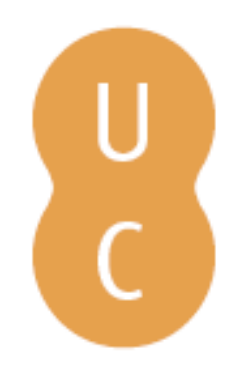

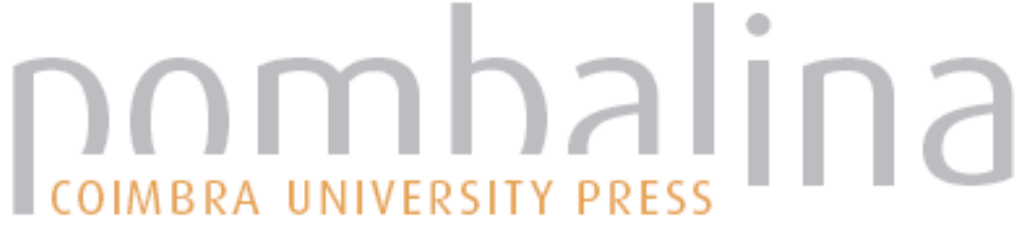

\section{Representação do conhecimento: identidade ou esvaziamento da ciência da informação?}

\author{
Autor(es): $\quad$ Souza, Renato Rocha; Almeida, Maurício Barcellos \\ Publicado por: Imprensa da Universidade de Coimbra \\ URL \\ persistente: URI:http://hdl.handle.net/10316.2/31876 \\ DOI: $\quad$ DOI:http://dx.doi.org/10.14195/978-989-26-0319-3_13 \\ Accessed : $\quad$ 26-Apr-2023 11:05:46
}

A navegação consulta e descarregamento dos títulos inseridos nas Bibliotecas Digitais UC Digitalis, UC Pombalina e UC Impactum, pressupõem a aceitação plena e sem reservas dos Termos e Condições de Uso destas Bibliotecas Digitais, disponíveis em https://digitalis.uc.pt/pt-pt/termos.

Conforme exposto nos referidos Termos e Condições de Uso, o descarregamento de títulos de acesso restrito requer uma licença válida de autorização devendo o utilizador aceder ao(s) documento(s) a partir de um endereço de IP da instituição detentora da supramencionada licença.

Ao utilizador é apenas permitido o descarregamento para uso pessoal, pelo que o emprego do(s) título(s) descarregado(s) para outro fim, designadamente comercial, carece de autorização do respetivo autor ou editor da obra.

Na medida em que todas as obras da UC Digitalis se encontram protegidas pelo Código do Direito de Autor e Direitos Conexos e demais legislação aplicável, toda a cópia, parcial ou total, deste documento, nos casos em que é legalmente admitida, deverá conter ou fazer-se acompanhar por este aviso.

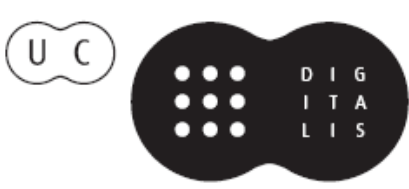


Maria Manuel Borges

Elias Sanz Casado

Coordenação

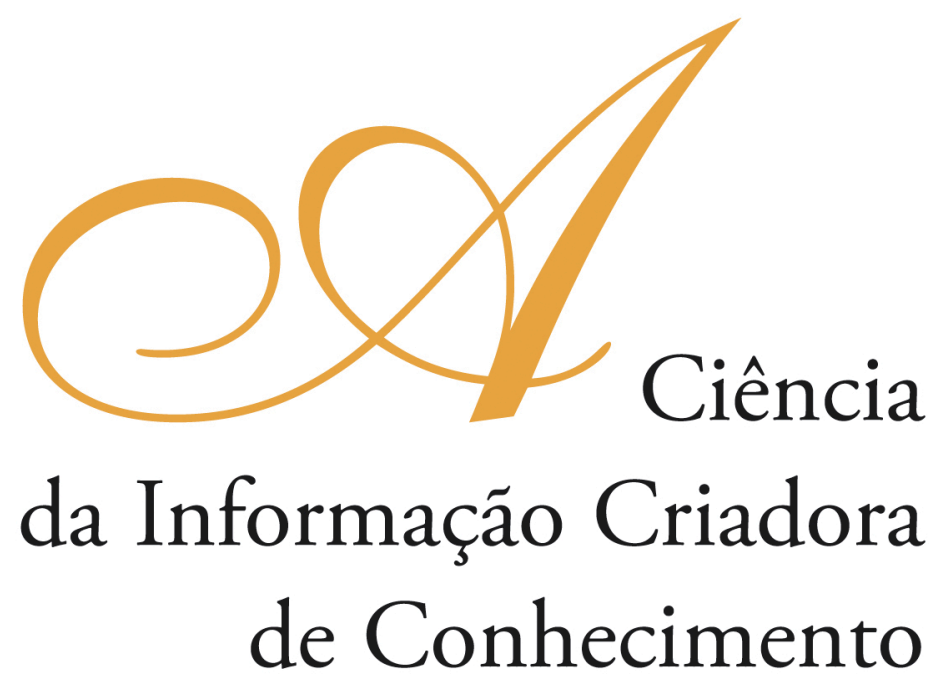

Vol. I

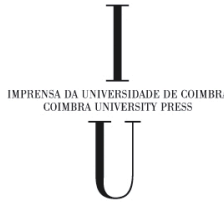

- COIMBRA 2009 
RePREsentaÇÃo do CONHECIMENTO:

IDENTIDAdE OU ESVAZIAMENTO DA Cî̂NCIA DA INFORMAÇÃo? ${ }^{\text {I }}$

\author{
Renato Rocha Souza \\ Universidade Federal de Minas Gerais (Brasil) \\ Maurício Barcellos Almeida \\ Universidade Federal de Minas Gerais (Brasil)
}

\title{
Resumo
}

Discute, sob uma perspectiva crítica, alguns dos objetos de pesquisa atualmente desenvolvidos na ciência da informaçáo e aqueles que, embora sejam decorrentes do processo de evolução tecnológica sobre questóes oriundas no escopo da biblioteconomia, têm sido absorvidos ou mais bem desenvolvidos em outras áreas do conhecimento. Questiona ainda a primazia e a quantidade de pesquisas interdisciplinares na área e tece comentários sobre o que pode redundar desse processo para o futuro da Ciência da Informaçáo.

\begin{abstract}
Discusses, under a critical point of view, some of the research themes currently being developed in the library and information science area and those that, in spite of being consequences of the technological evolution of subjects that arose in the librarianship field, are being absorbed and well developed by other knowledge fields. It also questions the primacy and the ratio of interdisciplinary approaches in the field and states some comments over the Information Science foreseen future.
\end{abstract}

\section{Introdução}

Discutir o estatuto epistemológico da Ciência da Informação não é tarefa fácil. As questôes conceituais subjacentes à área são, por vezes, foco de reflexôes tão apaixonadas e profundas, que os seus objetos de estudo por vezes ficam obnubilados, relegados a um segundo plano. Tendo em seus textos seminais trabalhos tão diversos como o de Shannon e Weaver (1949), e partindo de um conceito táo multifacetado, como exposto em Barlow (1994), Hofkirchner (1999), e Capurro (2003), é surpreendente que outros autores esbocem certa concordância sobre o que se abriga sob sua égide (Borko, 1968; Zins, 2009). Sem embargo, não é sem percalços que uma área relativamente nova, em comparação com as chamadas "hard sciences", se sedimenta.

\footnotetext{
${ }^{1}$ Este trabalho contou com o apoio do CNPq, a agência governamental brasileira de fomento à pesquisa.
} 
No tocante à esta relativa novidade, Wersig (1993) nos chama a atenção para a necessidade de uma perspectiva pragmática e evolucionária, aliada às tentativas de construção teórica, e de uma aceitação da complexidade inerente uma ciência interdisciplinar, de forma que os objetos de pesquisa empírica e as interfaces com outras áreas sejam subsídios para a construção e reconstrução permanentes da área. Em seu texto, descreve o profissional de CI fazendo uma analogia ao "Weaving Bird", pássaro que constrói seus ninhos fazendo intrincadas e elaboradas teias, numa referência às "costuras temáticas" comuns à práxis do cientista da informação.

A questão que se coloca neste ensaio, imbuída de certa provocação - e de certa parcialidade - é fruto do testemunho de um inexorável esvaziamento da área como uma Ciência autônoma a partir da imbricação crescente dos objetos de pesquisa atualmente desenvolvidos em outras áreas - consolidadas ou não - do conhecimento. Isso redunda na diminuição substancial, migração - ou esvaziamento - daqueles que poderiam ser considerados objetos legítimos e atavicamente ligados à Ciência da Informação. Sob esta perspectiva, a reconstrução permanente exaltada por Wersig (2003) não vêem redundando no fortalecimento de uma ciência emergente e diferenciada pela abordagem interdisciplinar, mas no surgimento de uma nova CI, quase meta-ciência, progressivamente amorfa, e que se ancora em olhares peculiares e idiossincráticos sob objetos cada vez mais alheios. Este argumento será desenvolvido nos parágrafos a seguir.

\section{Panorama: o esvaziamento?}

Em sua célebre definição, BORKO afirma que a Ciência da Informação é:

"a disciplina que investiga as propriedades e comportamento da informaçáo, as forças que governam seus fluxos e os meios para processá-la, de modo a obter altos graus de usabilidade e acessibilidade. Está preocupada com aquele campo de conhecimento relacionado à origem, coleta, organizaçáo, armazenamento, recuperação, interpretação, transmissão, transformação e utilização da informaçáo. Isto inclui a investigação das representaçôes informacionais em sistemas naturais e artificiais, o uso de códigos para transmissáo eficiente de mensagens, e o estudo dos dispositivos e técnicas para processamento de informação, como os computadores e seus sistemas. É uma ciência interdisciplinar derivada de e relacionada a campos do conhecimento como matemática, lógica, lingüística, psicologia, computação, pesquisa operacional, artes gráficas, comunicação, biblioteconomia, administração e outros similares. Contêm componentes tanto das ciências puras - na medida em que questiona os objetos de estudo sem uma relaçáo necessária com suas aplicaçóes - quanto das ciências aplicadas, na medida em que desenvolve produtos e serviços (1968, tradução nossa)."

Não é motivo de celeuma que, com tal definição, virtualmente quaisquer dos objetos de pesquisa acadêmica na atualidade envolva algum componente ligado à Ciência da Informação. No entanto, é possível identificar um viés em tais entrelinhas: a Ciência da Informaçáo preocupa-se primariamente com processos de representação 
do conhecimento e de seus registros associados (representação da informação). É da natureza destes processos que a informaçáo sofra sucessivas abstraçóes, modelagens e representaçôes, de forma a ser organizada, transmitida, codificada, consumida.

Segundo Alvarenga (2003), estes processos de representação são de dois tipos: A representaçáo primária, que ocorre quando são criados documentos como objetos que representam o conhecimento, e a representaçáo secundária que visa à organizaçáo de documentos através da inclusão em sistemas referenciais, ou seja, através da criação de metadados. De todas as formas, a representação de informação e do conhecimento ocupa espaço seminal e fulcral na área, como desenvolvemos a seguir.

Apesar de alguma divergência, há razoável acordo sobre o momento e as causas do nascimento da Ciência da Informação (Pinheiro \& Loureiro, 1995; Dias, 2002). Esta surge para lidar com os problemas decorrentes do aumento da complexidade na gestão de acervos informacionais, na necessidade de adaptação das metodologias e da práxis oriundas dos campos da documentação e biblioteconomia e no surgimento de tecnologias automatizadas para estes fins. Entretanto, o final do século XX assistiu à rápida expansão das tecnologias da informação e a aceleração dos processos de transformação da informação - criação, representação armazenamento, organização, disseminação e consumo - fazendo com que as características que originalmente justificaram a criação de uma "Ciência da Informação", décadas atrás, sejam sentidos de forma exponencial.

A guisa de ilustração, observem-se os números que refletem a produção atual de registros de informaçáo (Souza, 2008): dados estimados sobre a produção mundial de conteúdo digital apontam para a cifra de 281 bilhóes de gigabytes gerados apenas no ano de 2007, ou seja, quase 50 gigabytes para cada ser humano vivo. Isto equivale a mais de cinco milhôes de vezes o conteúdo de todos os livros já escritos. Supóe-se que o número total de páginas na web seja superior a um trilhão. E em 2006, estimava-se que havia cerca de 6 milhóes de vídeos no site Youtube, com taxa de crescimento de $20 \%$ ao mês. Comparados com os cerca de 50 milhóes de minutos da vida de uma pessoa longeva, já temos hoje seguramente muito mais conteúdo disponível do que um ser humano poderia assistir, mesmo se decidisse dedicar toda a sua vida para tal.

As redes móveis, os dispositivos celulares, os leitores de livros digitais como o Kindle, as bibliotecas digitais e os conceitos emergentes como o de wearable computing têm continuamente mudado contextos, encurtado os ciclos, reinventado os suportes materiais e tornado cada vez mais orgânica nossa relação com os registros de informação. Há um desencaixe progressivo, fazendo ruir as permanentes ligaçôes entre informação e seus suportes usuais para registro e consumo, com as tecnologias digitais. A organizaçáo destas imensas massas de dados necessita de novas e criativas soluçóes; nunca se precisou tanto de uma Ciência da Informação para orquestrar estes esforços.

Não obstante, esta "ecologia técnica" que pretensamente favoreceria um renovado fôlego para a área - na medida em que multiplica os problemas informacionais decorrentes, e aumenta as possibilidades para suas soluções - tem, ironicamente, catalisado a migração paulatina de objetos de pesquisa genuínos para outras áreas do conhecimento. Como exemplo, artefatos sociotécnicos como as bibliotecas digitais, instrumentos de representaçáo do conhecimento como as ontologias, processos tais como a modelagem de domínios para desenvolvimento de software, o estudo de sistemas de informação e seus variados contextos de uso; se não considerados como propriamente 
pertencentes, ao menos têm sido ativamente pesquisados em áreas consolidadas - como a lingüística, antropologia ou a sociologia - mas também em campos mais recentes, como a Ciência da Computação, a área de Sistemas de Informação, a Engenharia de Software, dentre outras.

Por outro lado, temas como "responsabilidade social", "interdisciplinaridade e transdisciplinaridade", "informação e trabalho" e "sociedade da informação" (Ancib, 2009) - não obstante relevantes, e evidentemente legítimos para uma ciência que é tanto social quanto aplicada - vêm direcionando o foco da área para os aspectos mais sociais (e possivelmente fronteiriços). Do mesmo modo, a ascensão de pesquisas em temáticas ligadas à administração, como Gestão do Conhecimento e Inteligência Competitiva, aproximam a CI de campos como a Administração e Engenharia de Produção, mas contribuem para a difusão das suas fronteiras e a dissolução de sua identidade.

Para distinguir aquilo que é pertinente, e o que se afasta da identidade científica nuclear, há que se delinear as linhas de corte. No caso da administração, por exemplo, uma aproximação legítima se daria ao lidar com os insumos de informação que compóem as atividades de gestão, refletidos nas seguintes questôes: Quais os fluxos ou objetos informacionais inerentes aos processos de gestão? Como estes variam ao longo do tempo? De quais partes são compostos? Quais as suas características? São compostos por elementos generalizáveis ou são exemplos desses elementos? Quais são as relaçôes entre esses insumos que compóem as atividades? Como devem ser representados nos diversos contextos sociais? Como devem ser representados em sistemas de informação? Tais questóes, dentre outras, proporcionam entendimento da realidade subjacente, e resultam na possibilidade de organização e representação dos elementos constituintes dessa realidade. Apenas após esse tipo de "tratamento", os administradores podem definir estratégias e tomar decisões, em seu escopo de trabalho, o qual é diferente daquele em que atua o profissional de CI. O profissional de CI, assim como o do bibliotecário, executa trabalho de assessoria a usuários e outros profissionais.

No caso da Sociologia, não parece razoável criar uma dicotomia entre informação e o contexto social, visto que são intrinsecamente ligados. Entretanto, cabe refletir em cada abordagem o que se considera um "meio" e o que se considera um "fim". $\mathrm{Na}$ Sociologia, acredita-se, usam-se todos meios disponíveis, metodologias qualitativas e quantitativas, para estudar a estrutura social e a atividade humana. O contexto social, para a Sociologia, é assim um fim. No caso da CI, a informação é o fim, e a Sociologia, um meio para estudar aspectos da informação, quando essa se encontra inserida em um contexto específico: a informação disseminada em uma empresa está posicionada em contexto social diferente da informação que é produzida em uma universidade. Não se trata, absolutamente, conforme já mencionado, de negar a legitimidade das contribuições de outras áreas, e sim de situá-las adequadamente no âmbito das questóes historicamente ligadas a CI.

Em artigo de 2003, Araújo traça o caminho da Ciência da Informação rumo a esta configuração de Ciência Social, hoje dominante, afastando-se talvez de suas origens calcadas em uma abordagem positivista. Tal aproximação possibilitou à nascente ciência diferenciar-se com uma perspectiva pós-moderna (Wersig, 2003; Cardoso, 1996), adequada aos paradigmas de uso e usuários que surgiram nas últimas décadas do século XX. Em compensação, a mudança de enfoque se deu em detrimento dos aspectos mais nucleares e aplicados, que ajudariam a conferir uma identidade duradoura a um 
campo eternamente em construção. Da mesma maneira que se encontra dificuldade em definir a Ciência da Informação como uma Ciência aplicada, discutem-se quais seriam as aplicaçóes seriam naturalmente decorrentes desta condição.

\section{Representação do Conhecimento: a identidade?}

No tocante aos processos de representação da informaçáo e do conhecimento, táo atavicamente ligados às origens da área, corre-se o risco de tornar-se a CI um espectador passivo de um rapidamente cambiante panorama. Apesar de se ter primazia no estudo e construção de instrumentos como as linguagens documentárias e interfaces de sistemas de informação, estes temas são hoje associados às ciências mais técnicas, que com mais propriedade os têm incorporados aos seus fazeres e construtos.

Observem-se os progressos realizados pela Ciência da Computação no escopo da Web Semântica e no campo específico dos Knowledge Organization Systems (W3C, 2009; Nkos, 2009), das tecnologias e metodologias para construção de ontologias (Silva, 2008), nos Sistemas de Recuperação de Informação (Souza, 2006) e nos processos de análise de domínios e modelização (Wand, Storey e Weber, 1999). Há muito que estas áreas deixaram de ser provedoras de tecnologias e sistemas, para tornarem-se produtoras de conhecimento, ensejando novos diálogos e repertórios de parte da CI. Exemplos de áreas relativamente novas e pujantes náo faltam, como o Processamento de Linguagem Natural e a Lingüística Computacional, além de uma recrudescida Inteligência Artificial, que vêm desenvolvendo pesquisas em classificação e indexação automáticas, construção automática de ontologias, análise do discurso, dentre outras.

A pesquisa em ontologias constitui-se em um bom exemplo para análise da $\mathrm{CI}$, em seu aspecto original, ligado às suas raízes de organização da informaçáo, e da CI interdisciplinar e multifacetada. Também nesse caso cabe distinção similar aquela aplicada (seção 2) à Administração e à Sociologia, de forma a verificar em que aspectos as pesquisas em ontologias se aproximam das abordagens caras ao núcleo principal da CI.

Segundo Obrst, Hughes e Ray (2006), a pesquisa em ontologias consiste de diferentes perspectivas provenientes das diferentes comunidades envolvidas: Ciência da Computação e Inteligência Artificial, por exemplo, Guarino (1998), Gruber (1993); Ciência da Informação e Biblioteconomia, por exemplo, Vickery (1997), Søerguel (1997); Lógica e Filosofia, por exemplo, Smith (2003). A diversidade de campos de pesquisa e a explosão de publicaçôes sobre ontologias verificada a partir da década de 90 têm gerado interpretaçóes equivocadas. Muitas vezes, as ontologias são consideradas aplicaçóes puramente computacionais; em outros casos, considerase que as contribuiçôes provenientes da Filosofia são por demais abstratas para gerar resultados práticos.

De fato, uma avaliação sobre pesquisas e publicações sobre ontologias (Smith, 2003) demonstra que, aquilo que tem sido chamado de "ontologia", muitas vezes consiste apenas de consideraçóes relacionadas a Semântica Formal, a Teoria dos Modelos e a Teoria dos Conceitos. Tomando-se a Teoria dos Conceitos, vislumbra-se a proximidade com teorias utilizadas na CI (Dahlberg, 1974). A questão fundamental, entretanto, é que a Teoria do Conceito considera que "conceito" é uma entidade localizada na mente 
das pessoas, uma proposta similar a da Psicologia (Margolis \& Laurence, 1999). Essa visão "conceitualista", apesar de servir a diversos propósitos na CI como, por exemplo, em instrumentos como os vocabulários controlados, não se adéqua a realidade atual, caracterizada pelo uso de computadores. Sistemas automatizados e computadores se tornam elementos obrigatórios frente ao grande volume de informação disponível. E computadores necessitam de representaçóes formais.

Representaçôes formais podem ser resultado do estudo de ontologias formais, as quais tem raízes em Aristóteles ${ }^{2}$, $\mathrm{Kant}^{3}$, Brentano ${ }^{4}, \mathrm{Husserl}^{5}$, dentre outros. Os princípios subjacentes a criação dessas representaçóes formais têm sido utilizados em diversas áreas sobre o rótulo de "ontologia aplicada". Pode-se imaginar que, uma vez que as ontologias carecem de representaçóes formais, devem ser aplicaçôes da computação. Nada está mais distante da realidade: nesse contexto, a palavra "formal" não diz respeito a formalismos matemáticos ou lógicos, mas a "teoria das formas", ao estudo dos objetos, de suas partes, suas características, dentre outras (Smith, 2003). A representação no nível requerido para uso por um computador, o qual é um artefato com limitações evidentes, exige um trabalho de organização e entendimento da realidade característicos da prática em CI.

As pesquisas em ontologias, agregando teorias fronteiriças a CI, podem facilitar a aplicação do conhecimento sobre organização e representação, acumulado na área nos últimos cem anos, em insumos baseados em mídias digitais, prevalentes no mundo atual. Sejam ontologias, vocabulários controlados, terminologias ou outros instrumentos, fica evidente a importância da representação do conhecimento no conjunto interdisciplinar que se tornou a CI. Talvez, falar em identidade da área, diz respeito a resgatar tal importância. Cabe ainda enfatizar que, uma vez mantida a identidade epistemológica, o surgimento de novos instrumentos não requer a desconsideração de outros, conforme nos lembra Morin (2000, p. 2005): "a caminhada pelo pensamento [...] consiste em fazer ir e vir, incessantemente, entre certezas e incertezas [...]. Não se trata de abandonar os princípios da ciência clássica [...] mas de integrá-los em um esquema mais rico".

\section{Consideraçóes Finais}

Nas universidades americanas e européias a questão parece estar melhor equacionada, na medida em que surgem as escolas de "estudos de informação", e grupos interdisciplinares que acolhem os perfis necessários para exercer esta interdisciplinaridade sociotécnica. Nos Estados Unidos, um exemplo dessa discussão é o chamado movimento $i$-school, no qual um grande número de universidades adotou novas denominaçóes, posturas e mesmo currículo em escolas e deptos de pesquisa relacionados à informação (Detlefsen, 2008). Embora se estudem temas como Knowledge Management, as linhas

\footnotetext{
${ }^{2}$ Aristóteles (384-322 a.C.), filósofo grego.

3 Immanuel Kant (1724 - 1804), filósofo alemão.

${ }^{4}$ Franz C. H. H. Brentano (1838 - 1917), filósofo alemão.

5 Edmund G. A. Husserl (1859 - 1938), filósofo austríaco.
} 
mestras que definem a área não se distanciam completamente dos aspectos nucleares; realizando, no entanto, uma costura que abrange a periferia temática sob uma perspectiva central (Wikipédia, 2009).

Os congressos da Isko (2009) também denotam uma clara direção que visa a abrangência, mas mantêm o prumo teórico. A incorporação de temáticas que sugeririam um viés social como as folksonomias acontece no esteio dos sistemas de organização de informação.

No Brasil, entretanto, observa-se sob muitos pontos de vista uma deriva conceitual e epistemológica. Enumeramos alguns exemplos:

- O trabalho de Maia (2008), que demonstra a impossibilidade de realizar um agrupamento (cluster) conceitual de documentos apresentados no ENANCIB a partir de palavras-chave, tamanha a disparidade temática na área da Ciência da Informação;

- O extenso estudo de Silva et al, (2006), que aponta o tema "Informação, Cultura e Sociedade" como o que contém o maior número de linhas de pesquisa, segundo o CNPq, sendo responsável por quase $20 \%$ das linhas de pesquisa da CI no Brasil. O estudo mostra um percentual inferior a $25 \%$ para os estudos aplicados da CI.

No momento, os autores estão finalizando um estudo das distribuições temáticas das publicaçóes que possuem conceito Qualis A na área. Os primeiros resultados confirmam a inexorável tendência à diversidade.

Uma das agruras de ser a CI tão francamente interdisciplinar é a perspectiva de ver evanescer sua disciplinaridade, tão importante para a construção e preservação de sua identidade. Nas palavras de Francelin (2003), a CI experimenta hoje a necessidade de utilizar a receita que ela mesma propôs à biblioteconomia, ou seja, rever seus princípios e fundamentos de construção científica.

Conclui-se, na linha desta parábola, com a situação hipotética de um pretenso diálogo entre Biblioteconomia e Ciência da Informação, em que a primeira diria: "Dême um futuro, que lhe confiro um passado". Há que cuidarmos para que o futuro não seja tornar-se um nicho dentre outras áreas do conhecimento. E que, ao invés de um Weaving Bird de Wersig, o profissional da informação não se torne uma "Rêmora", alimentando-se das sobras temáticas de aquilo que se desenvolve com maior propriedade em áreas do conhecimento diversificadas e mais pujantes.

\section{Referências bibliográficas}

Alvarenga, L. (2003). Representação do Conhecimento na perspectiva da Ciência da Informação em Tempo e espaço Digitais. Retrieved July 28, 2009, from http://www.periodicos.ufsc. br/index.php/eb/article/view/97

Ancib. Histórico do Enancib. Retrieved March 2, 2009, from http://www.ancib.org.br/enancib/ historico-do-enancib/

Araújo, C. A. A. (2003). A ciência da informação como ciência social. Ciência da Informação, 32(3), 21-27.

\footnotetext{
${ }^{6}$ Peixe parasita que se acopla à barriga de peixes maiores para aproveitar-lhe dos restos de alimentos
} 
Barlow, J. P. (1994). A taxonomy of information. Bulletin of the American Society for Information Science, 13(17). Retrieved March 2, 2009, from http://findarticles.com/p/ articles/mi_qa3633/is_199406/ai_n8713489/?tag=content;col1;

Borko, H. (1968). Information science: what is this? American Documentation, 19 (3-5), 03-05.

Capurro, R. (2003). The Concept of Information. Annual Review of Information Science and Technology (ARIST), 37(8), pp. 343-411.

Cardoso, A. M. P. (1996). Pós-Modernidade e informação: conceitos complementares? Perspectivas em Ciência da Informação, 1(1), 63-79.

Dalberg, I. (1974). Towards a theory of concept. International Classification, 1(1), 12-18.

Detlefsen, E. G. (2008) What's is a name?: The I-Schools Project. Medical Library Association News, 28(3), 1-17.

Dias, E. J. W. (2002). O específico da ciência da informação. In M. Aquino (Ed.). O campo da ciência da informação: gênese, conexões e especificidades (po. 87-99). João Pessoa: Editora Universitária.

Francelin, M. M. (2003). A epistemologia da complexidade e a Ciência da Informaçáo. Ciência da Informação. 32(2), 64-68.

Guarino, N. (1998). Formal ontology and information systems. In N. Guarino (Ed.). Formal ontology in information systems (pp. 3-15). Amsterdam: IOS Press.

Gruber, T. (1993). What is an ontology? Retrieved September 14, 2002, from http://www-ksl. stanford.edu/kst/what-is-an-ontology.html

Hofkirchner, W. (1999). The Quest for a Unified Theory of Information. In W. Hofkirchner (Ed.). Proceedings of the Second International Conference on the Foundations of Information Science (pp. 9-30). Amsterdam: Gordon and Breach.

ISKO - International Society for Knowledge Organization. ISKO Chapters. Retrieved July 2, 2008, from http://www.isko.org/chapters.html

Maia, L. C. G. (2008). Uso de Sintagmas Nominais na classificação de documentos eletrônicos. PhD Thesis, Belo Horizonte, BR, Universidade Federal de Minas Gerais, Escola de Ciência da Informação.

Margolis, E., \& Laurence, S. (1999). Concepts: Core Readings. Cambridge: MIT Press.

Morin, E., \& Le-Moigne, J. L. (2000). A inteligência da complexidade. São Paulo: Editora Petrópolis.

Nkos (2009). Simple Networked Knowledge Organization Systems/Services. Retrieved March 21, 2009, from http://nkos.slis.kent.edu/

Obrst, L., Hughes, T., \& Ray, S. (2006). Prospects and possibilities for ontology evaluation: The view from NCOR. Procceding of the Fourth International Workshop on Evaluation of Ontologies for the Web at the 15th International World Wide Web Conference, Edinburgh, UK.

Pinheiro, L., \& Loureiro, J. (1995). Traçados e limites da ciência da informação. Ciência da informação, 24(1), 42-53.

Shannon, C. E., \& Weaver, W. (1949). The Mathematical Theory of Communication. Urbana: University of Illinois Press.

Silva, D. L. (2008). Uma Proposta Metodológica para Construção de Ontologias: uma Perspectiva Interdisciplinar entre as Ciências da Informação e da Computação. Dissertation, Belo Horizonte, BR, Universidade Federal de Minas Gerais, Escola de Ciência da Informação. 
Silva, E. L. et al. (2006). Panorama da pesquisa em Ciência da Informação no Brasil. Informação \& Sociedade: Estudos, 16(1), 159-177.

Smith, B. (2003). Ontology and information systems. Retrieved March 20, 2005, from http:// www.ontology.buffalo.edu/ontology(PIC).pdf

Søerguel, D. (1997). Functions of a thesaurus, classification and ontological knowledge bases. Retrieved December 12, 2003, from http://www.clis.umd.edu/faculty/soergel/soergelfctclass. pdf

Souza, R. R. Sistemas de recuperação de informações e mecanismos de busca na web: panorama atual e tendências, Retrieved March 2, 2008, from http://www.eci.ufmg.br/pcionline/ viewarticle.php?id=457\&layout $=$ abstract

Souza, R. R. (2008). Quando ignorar é preciso! Diversa, 11(2). 25-28.

Vickery, B. C. (1997). Ontologies. Journal of Information Science, 23(4), 227-286.

W3C. (2009). SKOS - Simple Knowledge Organization System. Retrieved March 2, 2009, from http://www.w3.org/2004/02/skos/

Wand, Y., Storey, V.C., \& Weber, R. (1999). An ontological analysis of the relationship construct in conceptual modeling. ACM Transactions on Database Systems, 24(4), 494-528.

Wersig, G.(1993). Information science: the study of postmodern knowledge usage. Information Processing \& Management, 29(2), 229-239.

Wikipedia. (2009). Information Science: Related fields and sub-fields. Retrieved June 2, 2009, from http://en.wikipedia.org/wiki/Information_science

Zins, C. (2009). Knowledge Map of Information Science: Issues, Principles, Implications. Retrieved March 3, 2009, from http://www.success.co.il/is/index.html 